\title{
Turbininių dujų skaitiklių atsakas ir dinaminė paklaida esant srauto pulsacijoms pagal sudètingus dèsnius
}

Jurij Tonkonogij ${ }^{1}$,

Stasys Šinkūnas²,

Andrius Tonkonogovas',

Arūnas Stankevičius ${ }^{1}$

${ }^{1}$ Šiluminiu irengimu tyrimu

ir bandymu laboratorija,

Lietuvos energetikos institutas,

Breslaujos g. 3, LT-44403 Kaunas

E-mail:jurij@mail.lei.lt
Sukurtas metodas, kuris anksčiau panaudotas turbininių dujų skaitiklių atsako ir dinaminès paklaidos skaitiniam modeliavimui esant paprastiems pulsacijos dėsniams, čia pritaikytas artimiems praktikai sudètingų pulsacijos dėsnių atvejams.

Raktažodžiai: turbininis dujų skaitiklis, srauto pulsacijos, sudètingas pulsacijų dèsnis, atsakas, dinaminè paklaida

${ }^{2}$ Kauno technologijos universitetas

\section{IVADAS}

Turbininiai dujų skaitikliai (TDS) yra plačiai naudojami gamtinių dujų apskaitai. Jiems būdinga vadinamoji dinaminè paklaida, kuri atsiranda pulsuojančiame sraute dèl TDS rotoriaus inercijos. Momentinis sukimosi dažnis atsilieka nuo einamosios debito vertès. TDS rodmenys greičiau artėja prie debito, kai pastarasis didèja, negu kai jis mažèja. Todèl atsiranda dinaminé paklaida, kurios ženklas visada teigiamas.

N. Lehmann [1], R. McKee [2], R. Cheeswright [3], B. Lee [4], K. Atkinson [5] ir keletas kitų mokslininkų atliko plačius dinaminès paklaidos tyrimus, kurie apibendrinti ISO dokumente [6]. Iki šiol visi rezultatai gauti analizuojant elementarius pulsacijų dèsnius - stačiakampí, sinusinị ir trikampị. Tačiau praktikoje TDS paprastai veikia esant sudètingiems pulsacijos dèsniams, kaip tai parodè R. Cheeswright, nagrinèjęs greičio pulsacijas dujotiekyje netoli slègio reguliatoriaus [7]. Kartais pasitaiko svyravimų, kai periodiškai kinta srauto kryptis.

Sukurtasis metodas [8], anksčiau pritaikytas TDS atsako ir dinaminess paklaidos skaitiniam modeliavimui esant paprastiems srauto pulsacijos dèsniams $[9,10]$, skirtas skaičiavimui esant ịvairiems sudètingiems srauto pulsacijos dèsniams.

\section{METODO PAGRINDAI}

Bet kuri laisvai numatyta debito kitimo laike kreive pakeičiama laiptuota linija aplink kreivę (1 pav.).

Kiekviename laiko žingsnyje $\Delta t_{i}$ TDS rodmenų skaičiavimui naudojama skaitiklio atsako ị stačiakampị (laiptinị) debito kitimą lygtis. Eksperimentai rodo, kad toks TDS atsakas vyksta eksponentiškai [11].

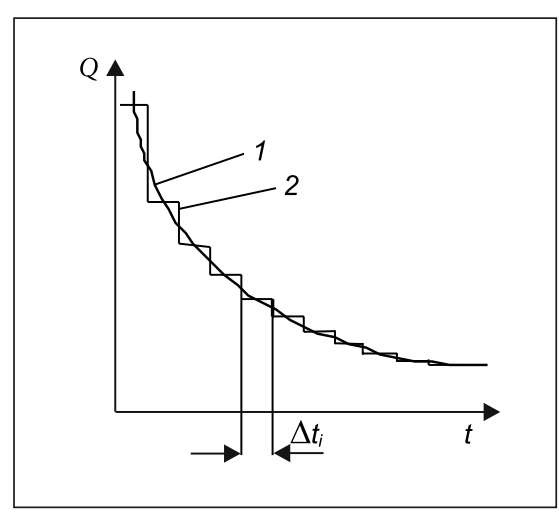

1 pav. Laisvai numatytos debito kitimo laike kreives (1) pakeitimas laiptuota linija (2). Laiptelio ilgis $-\Delta t_{i}$ 
Pagrindinis ir vienintelis proceso lemiamas parametras - TDS sukimosi inercijos indeksas $T$, kartais vadinamas inercijos laiko pastoviąja ir gana lengvai nustatomas eksperimentiškai [11].

Metodas leidžia atsisakyti iki šiol naudojamos tradicinès TDS rotoriaus sukimosi diferencialinès lygties su keliais sunkiai ir su didele neapibrèžtimi nustatomais parametrais. Šių parametrų visuma pakeičiama vieninteliu parametru $T$. Šis universalus metodas gali būti taikomas ne tik dujų skaitikliams, bet ir įvairių skysčių srauto matuokliams bei skaitikliams, tiek su sukamaisiais, tiek su kitais judančiais jutikliais. Jis iš esmès taikomas ne tik debito, bet ir kai kurių kitu parametrų, pvz., temperatūros, slègio ir greičio, matuokliams. Vienintelis metodo apribojimas - reikalavimas, kad matuoklio rodmenų kitimo dèsnis būtų pastovus nuo pat proceso pradžios arba kitimo désnis turi būti žinomas atsižvelgus i matuojamojo parametro vertę visose jo kitimo ribose.

\section{MATEMATINIS MODELIS}

Skaičiavimui galima pritaikyti baigtinių skirtumų metodą arba spręsti diferencialinę proceso lygti [8]. Šiuo atveju pasirinktas pirmas metodas, turintis tam tikrų skaičiavimo rezultatų apdorojimo, apibendrinimo ir pateikimo pranašumų.

Ieškomas TDS rotoriaus sukimosi dažnio $\omega$ pasiskirstymas laikotarpyje, kuris yra lygus srauto pulsacijos periodui $\Delta t_{0}=1 / f$. Šs laikotarpis buvo suskirstytas i pakankamai daug (n) laiko atkarpų $\Delta t_{i}$ :

$$
\Delta t_{j}=\Delta t_{0} / n
$$

Kiekvienoje tokioje $i$-oje atkarpoje ( $i$-ame laiko žingsnyje) galutinis sukimosi dažnis $\omega$ buvo nustatomas pagal žinomą galutinị dažnị $\omega_{\text {gal_(i-1) }}$, iš skaičiavimo ankstesniame (i-1)-ame žingsnyje, tuo tarpu jis yra ir pradinis $\omega_{\text {prad }}$ dabartiniame $i$-ame žingsnyje, pagal lygti:

$$
\omega_{g a l_{i}}=\omega_{Q}+\left(\omega_{p_{i}}-\omega_{Q}\right) \cdot \exp \left(-\Delta t_{i} / T\right)
$$

čia $\omega_{Q}$ - sukimosi dažnis, atitinkantis dabartinę momentinę srauto $Q$ vertę, nustatomas atsižvelgiant $\mathfrak{i}$ impulso vertę $k_{i m p}$ pagal lygti:

$$
\omega_{Q}=Q / k_{i m p} .
$$

TDS inercijos indeksas T nustatomas kiekviename žingsnyje, atsižvelgiant ị momentinę debito vertę pagal lygti [10]:

$$
T=C_{T} / Q_{j}^{m}
$$

Parametrai $C_{T}$ ir $m$ (4) lygtyje nustatomi eksperimentiškai konkrečiam TDS [10]. Kaip kraštinè sąlyga naudojama sukimosi dažnių intervalo $\Delta t_{0}$ galuose lygybè:

$$
\omega_{p r_{i}}=\omega_{g a l_{i-1}} .
$$

\section{IŠTIRTI DEBITO PULSACIJOS DĖSNIAI}

Skaičiavimai buvo atlikti esant keliems sudètingiems debito pulsacijos dèsniams, kurie yra artimi pasitaikantiems praktikoje [7]. Kiekvienas toks dèsnis gautas pagal Fourier principą, sudejjus elementarius įvairių amplitudžių ir dažnių kosinusinius désnius. Lentelèje pateiktos visų penkių ištirtų

\begin{tabular}{|c|c|c|c|}
\hline $\begin{array}{c}\text { Désnio } \\
\text { Nr. }\end{array}$ & Pulsacijos dèsnio lygtis & Impulso forma & $\begin{array}{l}\text { Koeficientas } C_{a} \\
\text { (6) lygtyje }\end{array}$ \\
\hline 1 & $\begin{array}{c}\bar{Q}=1+\Delta \bar{Q}(\cos (2 \pi t f)-0,25 \cos (4 \pi t f)+0,09 \cdot \cos (6 \pi t f)-0,05 \cdot \cos (12 \pi t f)+ \\
0,07 \cdot \cos (14 \pi t f))-0,04 \cdot \cos (18 \pi t f))\end{array}$ & & 42,71 \\
\hline 2 & $\bar{Q}=1+\Delta \bar{Q}(2 / 3 \Delta \cos (2 \pi t f)+1 / 2 \Delta \cos (4 \pi t f)-1 / 4 \Delta \cos (8 \pi t f))$ & & 48,93 \\
\hline 3 & $\bar{Q}=1+\Delta \bar{Q}(4 / 5 \cdot \cos (2 \pi t f)-1 / 4 \cos (8 \pi t f)+1 / 7 \cos (16 \pi t f)-1 / 12 \cos (20 \pi t f))$ & & 38,26 \\
\hline 4 & $\begin{array}{c}\bar{Q}=1+\Delta \bar{Q}(\cos (2 \pi t f)-0,35 \cos (6 \pi t f)+0,25 \cos (28 \pi t f)-0,09 \cos (46 \pi t f)- \\
0,05 \cos (96 \pi t f)+0,07 \cos (120 \pi t f))-0,04 \cos (150 \pi t f))\end{array}$ & & 35,60 \\
\hline 5 & $\begin{array}{c}\bar{Q}=1+\Delta \bar{Q}(\cos (2 \pi t f)-0,25 \cos (6 \pi t f)+0,09 \cos (10 \pi t f)-0,05 \cos (24 \pi t f)+ \\
0,07 \cos (30 \pi t f))-0,04 \cos (38 \pi t f))\end{array}$ & & 59,86 \\
\hline
\end{tabular}
dèsnių lygtys, impulso formos, šių dėsnių koeficiento $C_{a}$, kuris (6) lygtyje apibūdina apskaičiuotą ribinę dinaminę paklaidą, verte.

Lentelè. Ištirti pulsacijos dèsniai 
Atsako ì debito pulsacijas, t. y. TDS rodmenų kitimo laike, dinaminès paklaidos ir rodmenų pulsacijos, amplitudė apskaičiuota TDS MZ100 su metaline sparnuote, esant $D N=100 \mathrm{~mm}$, vidutiniam debitui $400 \mathrm{~m}^{3} / \mathrm{h}$ bei plačiose pulsacijų dažnio $f$ ir santykinès amplitudès $\Delta \bar{Q}$ ribose.

\section{TDS ATSAKAS}

TDS atsako skaičiavimo rezultatai parodyti 2 pav.

Esant gana mažiems pulsacijos dažniams ( $f=0,001-$ $0,01 \mathrm{~Hz}$ ) skaitiklio inercija beveik nepasireiškia, ir TDS skaitiklio rodmenys (rotoriaus sukimosi dažnis) gana tiksliai sutampa su debito kitimo kreive. Pulsacijos dažniui didejjant, inercija pasireiškia vis labiau, ir skaitiklio rodmenys vis daugiau atsilieka nuo tikrųjų momentinių skaitiklio rodmenų. Esant visiems pulsacijos dėsniams, TDS, dažniui didejjant, pirmiausia nustoja atsakyti ị nedidelių amplitudžių pulsacijos sudedamąsias, paskui - i vis didesnių amplitudžių dedamąsias.
Dažniui didejant, TDS rodmenų pulsacijos amplitudè mažeja, ši pulsacija slenka pagal fazę, ir jos dėsnis vis artèja prie kosinusinio dèsnio. Esant pakankamai dideliems pulsacijos dažniams (1-10) Hz eilès, dèl inertiškumo TDS beveik neatsako ị debito pulsacijas, jo sukimosi dažnis išlieka pastovus, tačiau jis išlieka didesnis už dažni, kuris atitinka vidutini debitą. Šis perteklius lemia TDS dinaminę paklaidą.

\section{TDS DINAMINE PAKLAIDA IR RODMENŲ PULSACIJOS AMPLITUDE்}

TDS MZ100 skaitiklio dinaminės paklaidos ir rodmenų pulsacijos amplitudès priklausomumas nuo dažnio, esant ịvairioms debito pulsacijos amplitudèms ir įvairiems debitams, parodytas 3 ir 4 pav. visiems išnagrinètiems pulsacijos dèsniams pagal lentelę.

Dinaminès paklaidos kitimo pobūdis kokybiškai toks, kaip ir paprastų pulsacijos dèsnių atvejais. Esant pakankamai mažiems pulsacijos dažniams, kai skaitiklio inercija

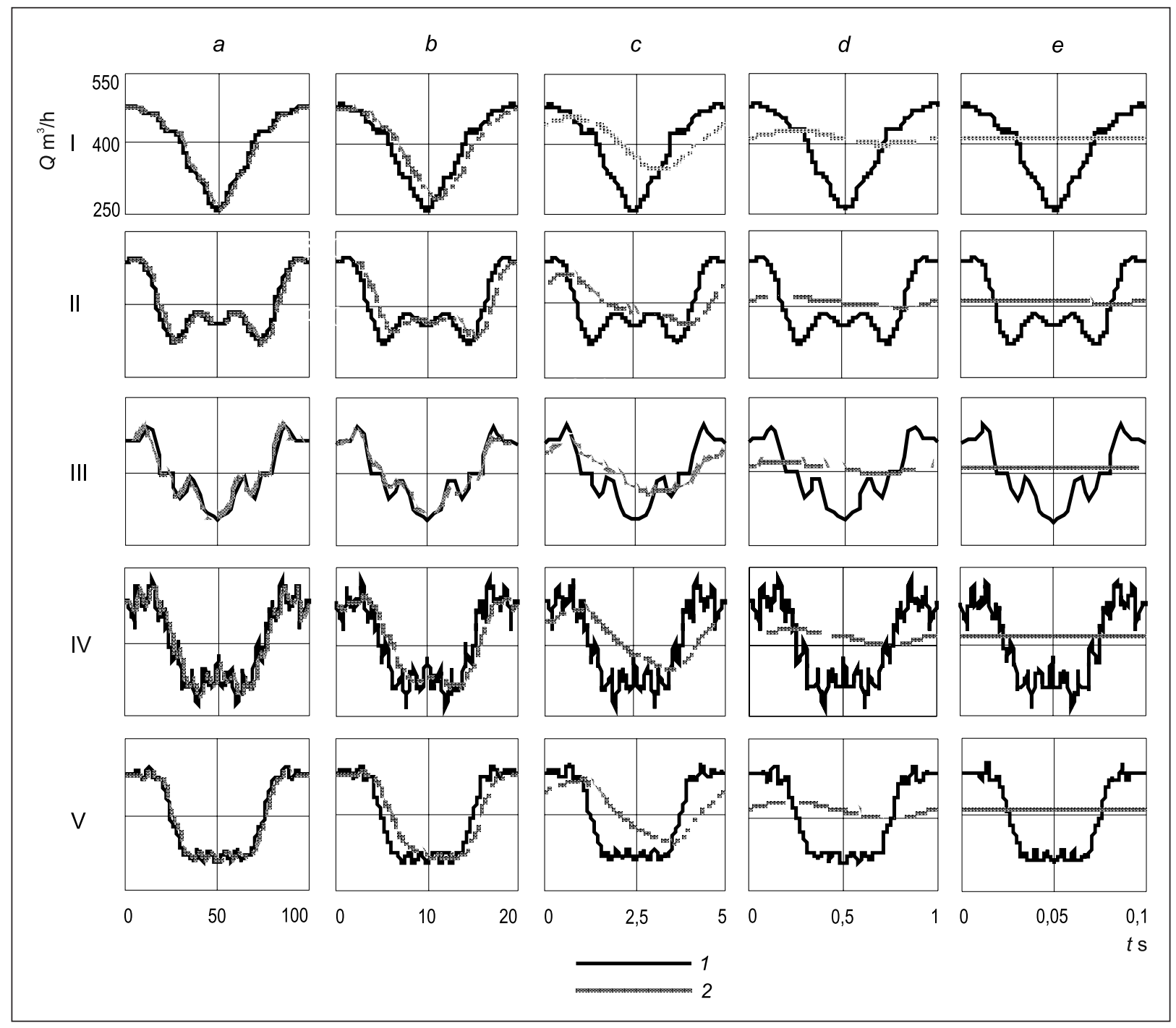

2 pav. TDS MZ100 su metaline sparnuote atsakas i debito pulsacijas. 1 - debitas, 2 - skaitiklio rodmenys; $\mathrm{I}-\mathrm{V}$ - pulsacijų desniai atitinkamai 1 lentelei; $a-e=0,01 ; 0,05 ; 0,2 ; 1 ; 10 \mathrm{~Hz} ; \Delta \bar{Q}_{s}=0,25$ 


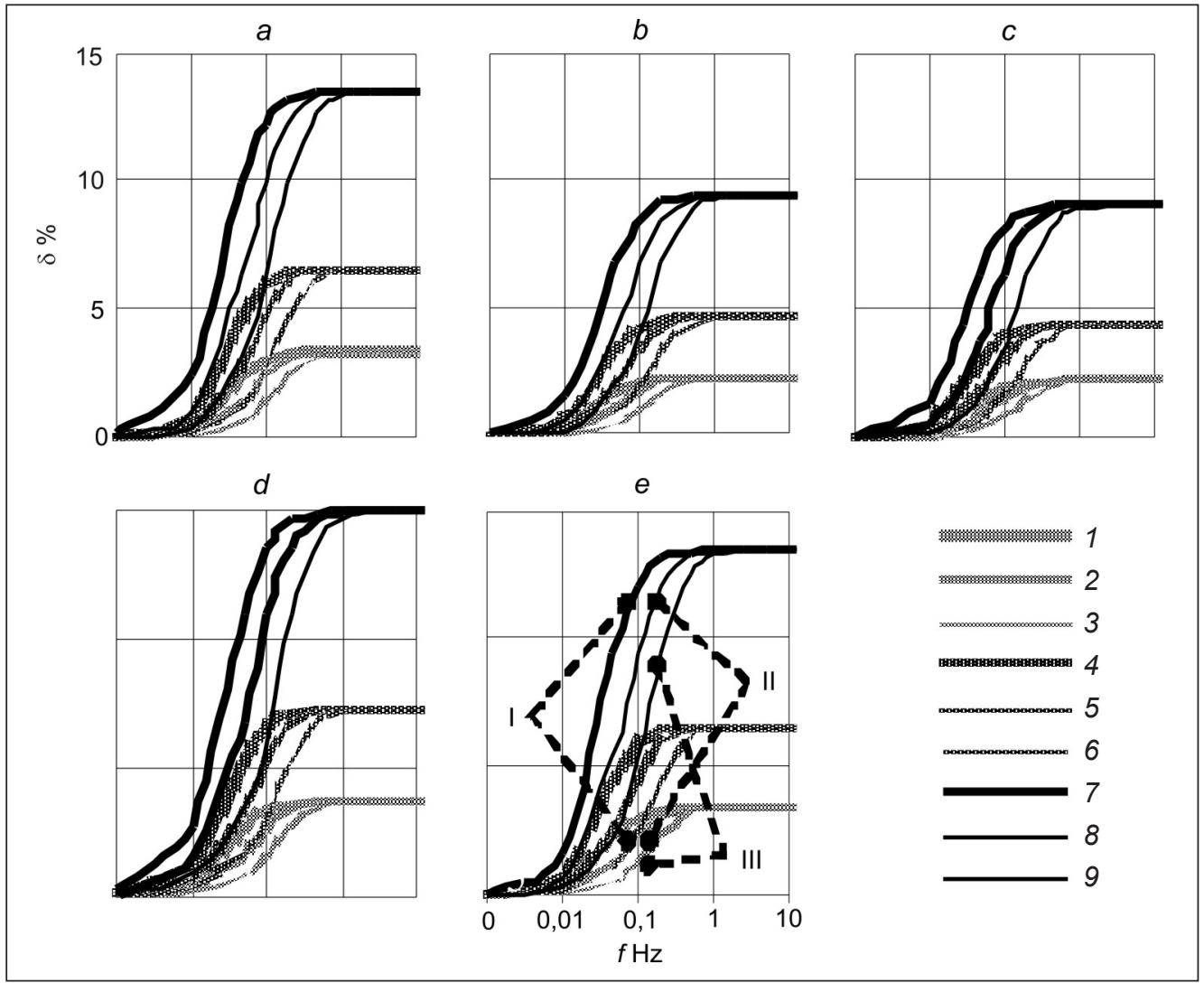

3 pav. TDS MZ100 skaitiklio dinaminės paklaidos priklausomumas nuo pulsacijos dažnio. $a, b, c, d, e-1-5$ pulsacijos désniai pagal 1 lentelę; I, II, Ш - debitas 100, 200, $400 \mathrm{~m}^{3} / \mathrm{h}$; atitinkamai 1-3, 4-6, 7-9- $\Delta \overline{\mathrm{Q}}=0,25 ; 0,35 ; 0,5$

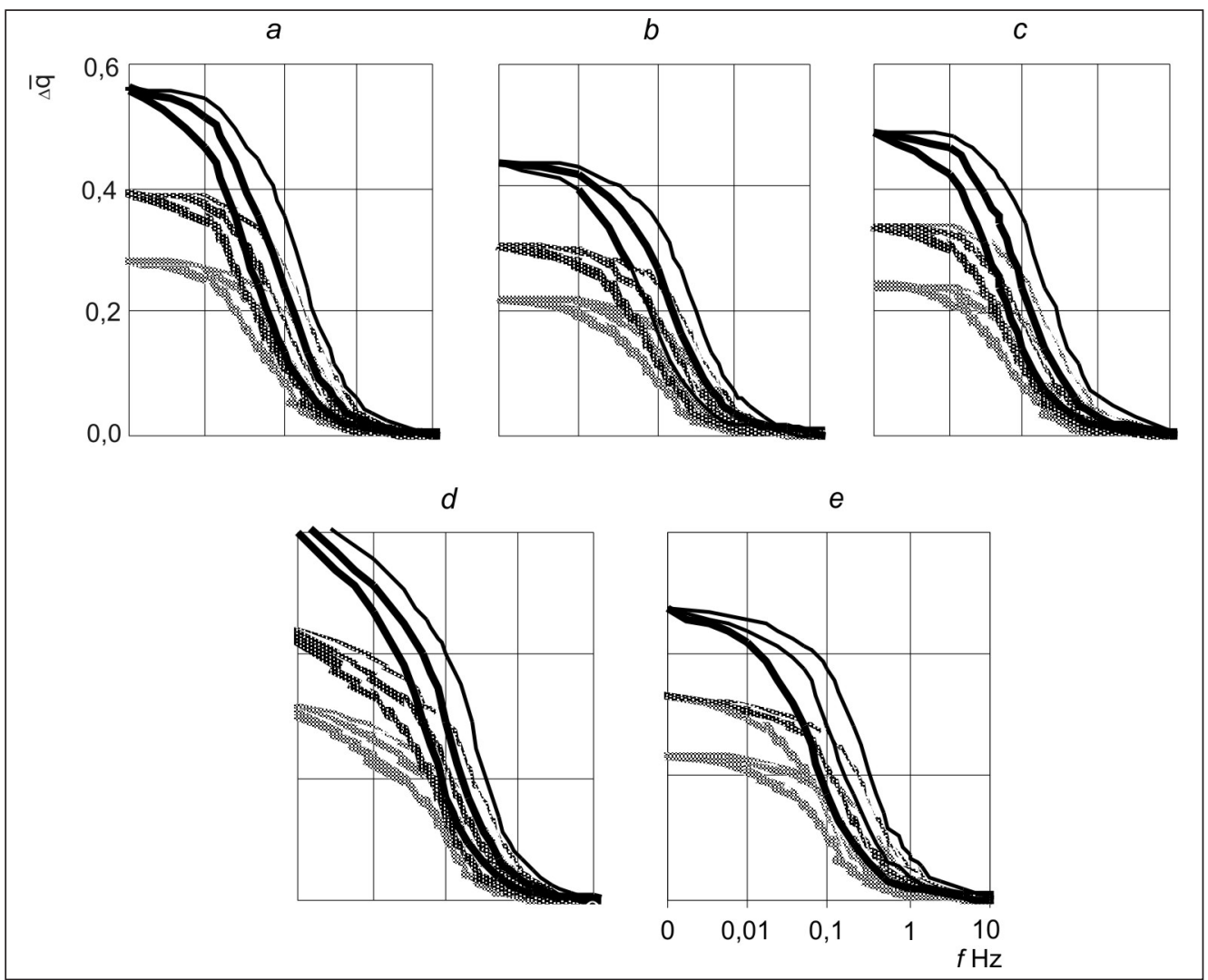

4 pav. TDS MZ100 skaitiklio rodmenų pulsacijos amplitudès priklausomumas nuo pulsacijos dažnio. Apibrěžimai - 3 pav. 


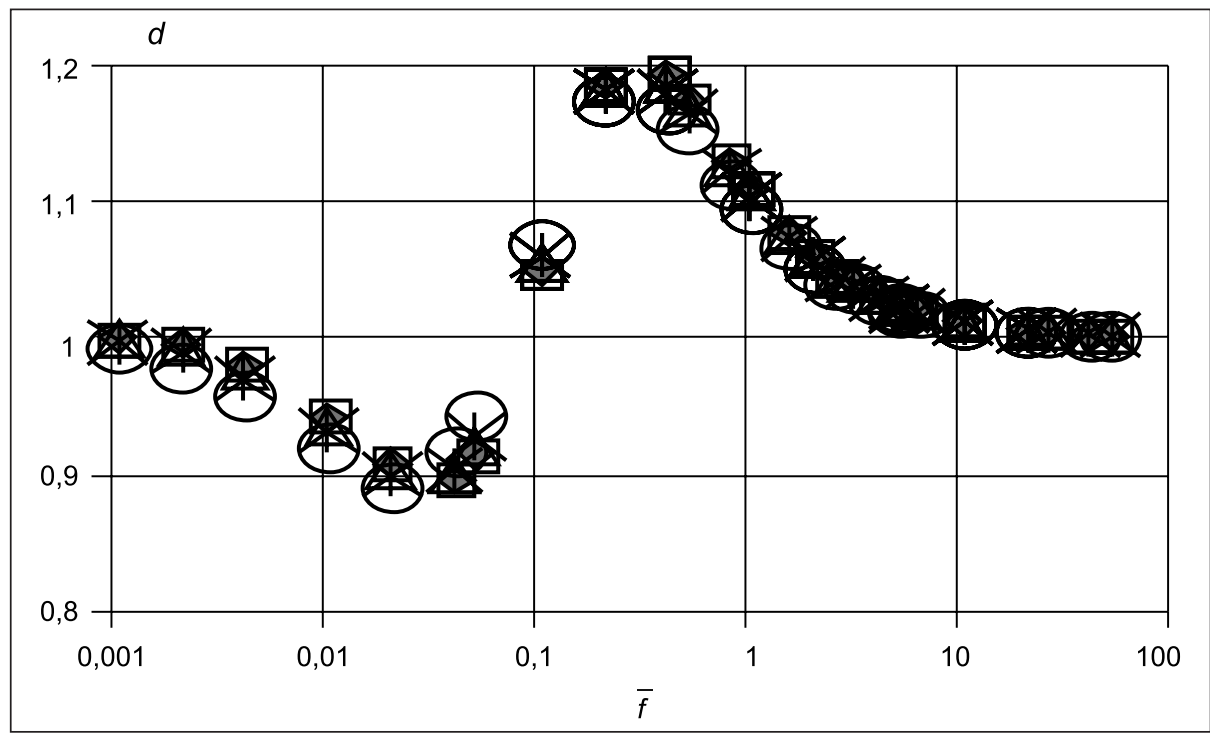

5 pav. Dinaminės paklaidos ir skaitiklio rodmenų pulsacijos amplitudès, atsižvelgus ị pulsacijos dažnį, santykinių dydžių sumos. 1 ir 2 - atitinkamai 1 ir 4 pulsacijos désniai

nepasireiškia, dinaminè paklaida artima nuliui. Dažniui didėjant dinaminè paklaida vis labiau didèja. Esant tam tikram dažniui paklaidos augimo tempas pasiekia didžiausią vertę ir pradeda mažèti. Tuo metu dinaminè paklaida didejja, kol nepasieks savo ribinès vertès $\delta_{r i b}$, esant dažniams $(1-10) \mathrm{Hz}$. Tai atsitinka TDS rotoriaus sukimosi dažniui nustojus pulsuoti ir tapus pastoviu. Taigi dinaminès paklaidos ir skaitiklio atsako priklausomybès nuo debito pulsacijos dažnio atitinka viena kitai. Šių priklausomumų pobūdis lygiai toks, kaip ir paprastų pulsacijos dèsnių atvejais.

Dinaminès paklaidos ir TDS rodmenų pulsacijos amplitudès priklausomumai nuo debito pulsacijos dažnio sutampa (3 ir 4 pav.). Šių dviejų parametrų nedimensinès sumos $\left(\Delta q / \Delta \bar{Q}+\delta / \delta_{\text {rib }}\right)$ priklausomumas nuo nedimensinio pulsacijos dažnio $\bar{f}=f \cdot T$ esant dviem sudètingiems pulsacijos dèsniams parodytas 5 pav.

Esant pakankamai mažoms ir didelèms pulsacijos dažnio vertėms suma yra lygi vienetui, esant tarpinėms vertėms - iki $20 \%$ nukrypsta į kažkurią pusę dèl pulsacijos dèsnio.

\section{RIBINĖ DINAMINĖS PAKLAIDOS VERTE்}

Ribinė dinaminès paklaidos vertė $\delta_{r i b}$ priklauso tik nuo santykinès debito pulsacijos amplitudès $\Delta \bar{Q}$. Ribinè dinaminès paklaidos vertè:

$$
\delta_{r i b}=C_{a} \Delta \bar{Q}^{2}
$$

Pastovioji $C_{a}$ šioje lygtyje priklauso tik nuo pulsacijos dèsnio. Esant paprastiems désniams (stačiakampis, kosinusinis ir trikampis) ši vertė yra atitinkamai $C_{a}=100,50$ ir 33,5. $C_{a}$ vertès esant sudètingiems pulsacijos dèsniams pateiktos lentelëje. Šios vertès artimos vertėms kosinusinio ir trikampio dèsnių atvejais.

\section{IŠVADOS}

1. Anksčiau mūsų sukurtas TDS atsako ị pulsacijas skaitinio modeliavimo ir dinaminès paklaidos skaičiavimo metodas pritaikytas artimiems praktikai sudètingiems pulsacijos dèsniams.

2. TDS dinaminè paklaida ir atsako (skaitiklio rodmenų) pulsacijos amplitudè susijusios tarpusavyje. Jų kitimo pobūdis esant sudettingiems pulsacijos dèsniams toks, kaip ir paprastų dèsnių atvejais.

3. Taikant pateiktą metodą dinaminè paklaida gali būti apskaičiuota esant bet kuriems pulsacijos dèsniams bet kuriomis, tarp jų ir lauko, sąlygomis.

Gauta 20110510

Priimta 20110620

\section{Literatūra}

1. Lehmann N. Dynamisches Verhalten von Turbinenradgaszahlern. Das Gas und Wasserfach - GWF. 1990. Vol. 4. P. 160-167.

2. McKee R. J. Pulsation effects on single- and two rotor turbine meters. Flow Measurement and Instrumentation. 1992. Vol. 3. No. 3. P. 151-166.

3. Cheesewright R., Bisset D., Clark C. Factors which influence the variability of turbine flow meter signal characteristics. Flow Measurement and Instrumentation. 1998. Vol. 9. No. 2. P. 83-89.

4. Lee B., Cheesewright R., Clark C. The dynamic response of small turbine flow meters in liquid flows. Flow Measurement and Instrumentation. 2004. Vol. 15. No. 5-6. P. 239-248.

5. Atkinson K. N. A software tool to calculate the overregistration error of a turbine meter in pulsating flow. Flow 
Measurement and Instrumentation. 1992. Vol. 3. No. 3. P. $167-172$.

6. ISO / TR 3313: 1998 - Measurement of fluid flow in closed conduits - Guidelines on the effects of flow pulsations on flow-measurement instruments.

7. Cheesewright R., Atkinson K. N., Clark C., Ter Horst G. J. P., Mottram R. C., Viljeer J. Field tests of correction procedures for turbine flowmeters in pulsate flows. Flow Measurement and Instrumentation. 1996. Vol. 7. No. 1. P. 7-17.

8. Tonkonogij J. The new equation of rotation of the turbine gas meter in unsteady flows. Energetika. 2009. Vol. 55. No. 3. P. $172-177$.

9. Tonkonogij J., Pedišius A. Numerical simulation of the turbine gas meters behavior in the pulsing flow. Journal of Heat Transfer Research. 2008. Vol. 39. No. 7. P. 559-570.

10. Tonkonogij J., Pedišius A., Stankevičius A. The new semiexperimental method for simulation of turbine flow meters rotation in the transitional flow. Proceedings of World Academy of Science, Engineering and Technology. Paris, France, July 2008. Vol. 30. P. 208-213.

11. Tonkonogij J., Pedišius A., Stankevičius A., Krukovskij P. The dynamic error of turbine gas meters in a pulsating flow. Industrial Heat Engineering. 2008. Vol. 30. No. 4. P. 85-93.
Jurij Tonkonogij, Stasys Šinkūnas, Andrius Tonkonogovas, Arūnas Stankevičius

\section{RESPONSE AND DYNAMIC ERROR OF TURBINE GAS METER IN FLOWS PULSATING ACCORDING TO COMPLEX LAWS}

Summary

The method previously applied for a numerical simulation of the response and dynamic error of a turbine gas meter in flows with a simple law of pulsation was applied to complex laws of pulsation similar to those that occur in practice.

Key words: turbine gas meter, flow pulsation, complex pulsation law, response, dynamic error

Юрий Тонконогий, Стасис Шинкунас, Андрюс Тонконоговас, Арунас Станкявичюс

\section{ОТКЛИК И ДИНАМИЧЕСКАЯ ПОГРЕШНОСТЬ ТУРБИННОГО СЧЕТЧИКА ГАЗА В ПУЛЬСИРУЮ- ЩИХ ПО СЛОЖНЫМ ЗАКОНАМ ПОТОКАХ}

\section{Резюме}

Предварительно разработанный метод численного моделирования отклика турбинного счетчика газа и его динамической погрешности в пульсирующих по простым законам потоках применен для моделирования поведения счетчика при пульсациях по близким к практике сложным законам.

Ключевые слова: турбинный счетчик газа, пульсация потока, сложный закон пульсации, отклик, динамическая погрешность 